\title{
Regulation of cGMP by phosphodiesterases (PDEs) in the central nervous system
}

\author{
Frank S Menniti*, Robin J Kleiman and Christopher J Schmidt
}

Address: CNS Discovery, Pfizer Global Research \& Development, Eastern Point Road, Groton, CT 06340, USA

Email: Frank S Menniti* - frank.s.menniti@pfizer.com

* Corresponding author

\author{
from $3^{\text {rd }}$ International Conference on cGMP Generators, Effectors and Therapeutic Implications \\ Dresden, Germany. 15-17 June 2007 \\ Published: 25 July 2007 \\ BMC Pharmacology 2007, 7(SuppI I):S48 doi:I0.II86/I47I-22I 0-7-SI-S48
}

This abstract is available from: http://www.biomedcentral.com/I47I-22I0/7/SI/S48

(C) 2007 Menniti et al; licensee BioMed Central Ltd.

It is becoming well established that metabolic inactivation of the cyclic nucleotides CAMP and cGMP is intimately involved in the regulation of cyclic nucleotidemediated signaling cascades. There are four families of PDEs that metabolize cGMP, PDE1, PDE2, PDE9, and PDE10, that are prominently and differentially expressed in the central nervous system. We have begun to characterize the role of these enzymes on cGMP metabolism in vivo using pharmacological and genetic approaches in mice. The effects of manipulating enzyme activity differ for each enzyme in different brain regions, corresponding to differential localization. However, the involvement of each enzyme also appears dependent on the level of activation of CGMP formation. These findings begin to define and differentiate the functions for the different PDEs in regulating cGMP signaling in the central nervous system. 